\title{
EFEKTIVITAS MINYAK BIJI Jatropha curcas UNTUK MENGENDALIKAN KEPIK PENGISAP POLONG KEDELAI Nezara viridula (HEMIPTERA: PENTATOMIDAE) DI RUMAH KASA
}

\section{EFFECTIVITY OF Jatropha curcas SEED OIL IN CONTROLLING GREEN STINK BUG Nezara viridula (HEMIPTERA: PENTATOMIDAE) IN WIRE HOUSE}

\author{
Asmanizar*, Aldywaridha, Edy Sumantri, Ardiansyah Putra Damanik \\ Program Studi Agroteknologi, Fakultas Pertanian \\ Universitas Islam Sumatera Utara Medan \\ Jl. Karyawisata Medan Johor \\ *Email:asmanizar_az@fp.uisu.ac.id
}

\begin{abstract}
Green Stink Bug Nezara viridula (Hemiptera: Pentatomidae) is an important pest on soybean. The yield losses could be qualitatively and quantitatively. Controlling by using synthetic insecticide caused negative impact. Hence, controlling by using botanical insecticide was as an alternative. The study was conducted at wire house, to know the effect of J. curcas seed oil concentration on N. viridula mortality, pod damaged, empty pod, seed damaged and dry seed weight. The J. curcas seed oil was obtained by Soxhlet Extractor. The concentration of J. curcas seed oil as the treatment, viz. 0\% (control); 0.125; 0.25 dan $0.5 \%$ (volume oil/volume solution, $v / v$ ), and the water as solution applied on soybean plant which was infested of ten $N$. viridula adult. The result showed all variable observed affected by J. curcas seed oil concentration. The 0.25 and $0.5 \%$ concentration showed the mortality reached 95.0 and $100 \%$ at 6 days after treatment, while, pod damaged was 7.34 and $1.84 \%$; empty pod was $25.32 \%$, seed damaged was 3.72 and $0.78 \%$ and weight of dry seed was 9.94 and $10.44 \mathrm{~g}$. The weight of dry seed at control treatment was $5.52 \mathrm{~g}$. The J. curcas seed oil at $0.5 \%$ of concentration has a potency to control $N$. viridula on soybean plant. There is a need further study to know the effectivity on soybean in the field.
\end{abstract}

Keywords: Effectivity, seed oil, Jatropha curcas, Nezara viridula

\begin{abstract}
ABSTRAK
Kepik Hijau_Nezara viridula (Hemiptera: Pentatomidae) adalah hama penting pada tanaman kedelai. Kerugian yang ditimbulkan dapat secara kualitatif dan kuantitaif. Pengendalian dengan insektisida sintetik dapat menimbulkan efek samping, sehingga pengendalian dengan insektisida botanis menjadi aternatif. Penelitian ini dilaksanakan di rumah kassa, dengan tujuan untuk mengetahui pengaruh konsentrasi minyak biji J. curcas terhadap mortalitas $\mathrm{N}$. viridula, polong terserang, polong hampa, biji terserang dan berat kering biji kedelai. Minyak biji J. curcas diperoleh dengan Soxhlet Extractor. Perlakuan adalah kosentrasi minyak biji J. curcas yaitu 0\% (kontrol); 0,125;
\end{abstract}


0,25 dan $0,5 \%$ (volume minyak/volume larutan, $v / v$ ) dengan pelarut air yang diaplikasikan pada tanaman kedelai yang telah diinfestasikan imago $N$. viridula. Hasil penelitian menunjukkan bahwa semua variabel yang diamati dipengaruhi oleh konsentrasi minyak biji J. curcas. Konsentrasi 0,25 and $0,5 \%$ menunjukkan mortalitas serangga mencapai 95,0 dan 100\% pada 6 Hari Setelah Aplikasi, sedangkan polong terserang adalah 7,34 dan 1,84\%; polong hampa $25,32 \%$, biji terserang 3,72 dan 0,78\%; dan berat biji kering 9,94 dan 10,44 g. Sementara itu berat biji pada perlakuan kontrol adalah 5,52 g. Minyak biji J. curcas pada konsentraasi $0,5 \%$ mempunyai potensi untuk mengendalikan serangan $N$. viridula pada tanaman kedelai. Kajian lebih lanjut diperlukan untuk menguji efektivitasnya pada pertanaman kedelai di lapangan.

Kata Kunci : Efektivitas, Minyak biji, Jatropha curcas, Nezara viridula

\section{PENDAHULUAN}

Kedelai merupakan salah satu tanaman bahan pangan penting di Indonesia di samping sebagai bahan pakan dan industri olahan. Kebutuhan kedelai di Indonesia meningkat setiap tahun seiring dengan pertambahan penduduk dan berkembangnya industri dengan bahan baku kedelai (Sudaryanto dan Swastika, 2007). Dalam upaya meningkatkan produksi kedelai, Dirjen Tanaman Pangan telah menetapkan program peningkatan produksi kedelai melalui intensifikasi dan ekstensifikasi. Demikian juga Pemerintah provinsi Sumatera Utara menargetkan menambah produksi kedelai demi mendukung program swasembada pangan (http://www.sumutprov.go.id).

Serangan hama penyakit pada tanaman kedelai merupakan salah satu kendala dalam mencapai produksi maksimal. Produksi kedelai mengalami penurunan sekitar $80 \%$ jika tidak dilakukan pengendalian hama (Marwoto, 2007). Salah satu hama yang menyerang tanaman kedelai adalah Kepik Hijau Nezara viridula (Hemiptera, Pentatomidae). Hama ini hadir pada pertanaman kedelai dimulai pada saat pembentukan bunga. Baik nimfa maupun imago menusuk polong dan biji dengan cara merusak kulit polong dan biji kemudian menghisap cairan biji. Kerusakan yang diakibatkan ditentukan oleh frekuensi serangan dan umur polong yang diserang. Serangan pada polong muda menyebabkan biji mengerut dan sering kali menyebabkan polong gugur. Serangan pada fase pertumbuhan polong dan pembentukan serta pengisian biji menyebabkan biji dan polong hampa dan mongering. Serangan pada fase pengisian biji menyebabkan kualitas biji turun oleh karena adanua bintik-bintik hitam pada biji dan biji juga menjadi keriput (Tengkano dan Sorhardjan, 1985; Panizzi et al., 2000). Pengendalian hama dengan insektisida merupakan cara yang umumnya dilakukan petani. Tujuan untuk cepat menurunkan populasi hama dan menyelamatkan produksi merupakan merupakan pertimbangan utama petani dalam menggunakan pestisida. Menurut Marwoto (2007) di beberapa tempat sebagai sentra produksi kedelai, petani umumnya masih menggunakan pestisida dalam mengendalikan hama.

Penggunaan pestisida sintetis dalam mengendalikan hama akan mengekibatkan timbulnya dampak negatif antara lain, terbunuhnya musuh alami 
dan hewan non - target, pencemaran lingkungan, efek residu serta hama berpotensi untuk menjadi resisten. Purwanta dan Rauf (2000) melaporkan bahwa aplikasi insektisida secara nyata menurunkan kelimpahan musuh alami hama. Penurunan populasi secara umum 20-78\% pada petak yang diaplikasi insektisida dibandingkan kontrol. Penggunaan insektisida sintetis juga akan menambah biaya produksi petani, sehingga keuntungan yang diperoleh akan menjadi lebih sedikit. Sebagai akibatnya petani beralih ke tanaman palawija lain yang lebih menguntungkan, sehingga berakibat pula luas pertanaman kedelai dan produksinya menjadi menurun (Haloho, 2014).

Bahan metabolit sekunder dari tanaman mengandung bahan bioaktif terhadap serangga hama. Berbagai tanaman telah diekstrak dan diuji pada serangga dan menunjukkan efek penolakan (repellent), anti makan (antifeedant), mematikan, menghambat peletakan telur dan mengganggu proses pergantian kulit ( Dodia et al., 2008; Prakash dan Rao, 1997; Isman, 2006). Ekstrak ranting Aglaia odorata mematikan hingga 98,7\% larva instar II Crocidolomia pavonana pada konsentrasi 0,5\% (Prijono, 1999). Ekstrak air biji Annona glabra dan A. squamosa pada 0,25\% $(0,25 \mathrm{~g}$ biji/100 $\mathrm{ml}$ suspensi) memiliki aktifitas insektisidal yang tinggi terhadap larva instar III Crocidolomia binotalis (Basana dan Prijono, 1994). Penggunaan insektisida botanis merupakan alternatif dari insektisida sintetis. Beberapa penelitian melaporkan penggunaan insektisida botanis terhadap hama pada tanaman di pertanaman di lapangan. Insektisida dengan formula dari minyak biji Azadirachta indica telah dibuat dalam formulasi Azadin 50 EC, dan hasil penelitian menunjukkan nilai LC50 sebesar 0,659\% $(0,550-0,781 \%)$ terhadap larva instar 2 hingga instar 4 (Ramadhan dkk., 2016).

Tanaman jarak pagar Jatropha curcas merupakan tanaman yang mudah tumbuh di Indonesia, dan umumnya ditanam di pekarangan dan dimanfaatkan sebagai tanaman obat. Penggunaan popular secara komersil akhir-akhir ini adalah sebagai bahan bakar bio-diesel (Khalil, 2013). Biji mengandung minyak hingga 34\% dengan komposisi kimia terdiri atas curcin, lection, forbol ester, esterase dan lipase. Beberapa penelitian telah membuktikan bahwa ekstrak dari biji mempunyai efek insektisidal. Adebowale dan Adedire (2006) melaporkan bahwa ekstrak kasar biji J. curcas mengandung bahan bioaktif yang bersifat insektisidal dan secara nyata dapat melindungi biji kacang tunggak (Vigna unguilata) dari serangan Callosobruchus chinensis. Bahan forbol ester dari minyak biji $J$. curcas juga mempunyai efek racun kontak dan menurunkan aktivitas makan larva Spodoptera frugiferda (Devappa et al., 2012).

Pada penelitian di laboratorium terdahulu, minyak biji jarak yang diperoleh melalui ekstraksi dengan Soxhlet mempunyai efek sebagai racun kontak dan racun perut terhadap Kepik Hijau Nezara viridula. Pada konsentrasi 0,25 dan 0,5\% menunjukkan hasil mortalitas kepik hingga 100\%(Unpublished). Penelitian ini bertujuan untuk mengetahui pengaruh konsentrasi larutan minyak biji J. curcas terhadap $N$. viridula pada tanaman kedelai di rumah kassa. 


\section{BAHAN DAN METODE}

Penelitian dilaksanakan di rumah kassa Fakultas Pertanian Universitas Islam Sumatera Utara pada bulan Juni hingga September 2019. Penelitian menggunakan Rancangan Acak Kelompok NonFaktorial dengan empat perlakuan konsentrasi minyak biji jarak (kontrol; 0,125\%; 0,25\% dan 0,5\%) dan enam ulangan. Minyak biji jarak diperoleh melalui ekstraksi dengan Soxhlet Extractor, di Laboratorium Fakultas Pertanian UISU.

Tanaman kedelai (Varietas Anjasmoro) dalam polibag dipelihara dengan satu tanaman setiap polibag (ukuran $35 \times 40 \mathrm{~cm}$ ) yang diisi dengan tanah top soil (bekas penanaman kedelai) dan dicampur dengan kompos dengan perbandingan 1:1. Pupuk NPK diberikan sebanyak $2 \mathrm{~g} /$ polibag pada saat tanaman berumur 7 hari sekaligus dilakukan penyungkupan dengan kawat kassa diameter $50 \mathrm{~cm}$ dan tinggi 100 cm setiap polibag.

Serangga uji imago $N$. viridula diperoleh dengan melakukan pembiakan massal dengan induk kepik diperoleh dari UPT Balai Benih Induk Tanjung Selamat. Kepik dipelihara pada kurungan serangga yang terbuat dari kayu ukuran 50x50x60 cm dan dikelilingi oleh kawat kassa. Selama pemeliharaan kepik diberi makan kacang panjang (Vigna unguilata ssp. sesquipedalis) yang telah dicuci dengan air mengalir dan diganti setiap dua hari. Generasi pertama dari hasil pembiakan massal digunakan sebagai bahan penelitian yaitu imago berumur 0-10 hari. Serangga diinfestasikan ke dalam tanaman kedelai pada umur 45 Hari Setelah Tanam (HST) sebanyak 10 ekor. Aplikasi insektisida botanis dari minyak biji jarak diaplikasikan satu hari setelah infestasi serangga uji sesuai dengan konsentrasi perlakuan. Variabel yang diamati adalah mortalitas $N$. viridula, persentase polong terserang, polong hampa, biji terserang dan produksi biji kering.

Pengaruh konsentrasi minyak biji J. curcas terhadap variable yang diamati diuji melalui Analisis of Variance dengan SPSS Statistic 24. Jika terdapat pengaruh perlakuan, maka dilanjutkan Uji Beda RataRata dengan Duncan's Multiple Range Test (DMRT).

\section{HASIL DAN PEMBAHASAN}

Hasil analisa statistik menunjukkan bahwa aplikasi minyak biji $J$. curcas dengan beberapa konsentrasi mempengaruhi mortalitas $N$. viridula. Tabel 1 menunjukkan data rata-rata mortalitas $N$. viridula dari 1 hingga 6 Hari Setelah Aplikasi (HSA).

Minyak biji J. curcas menunjukkan respons yang baik terhadap mortalitas imago $N$. viridula. Konsentrasi 0,5\% sudah menunjukkan efek kematian $38,33 \%$ pada 1 HSA, dan konsentrasi yang lebih kecil ( 0,25 dan $0,125 \%)$ secara konsisten menunjukkan pola yang sama. Respons kematian $N$. viridula merupakan efek dari kontak dengan larutan minyak biji J. curcas dan juga efek sebagai racun perut. Peluang kontak dengan larutan insektisida botanis minyak biji J. curcas lebih besar, yaitu kontak pada saat aplikasi maupun dengan tanaman yang terkena aplikasi insektisida botanis. Demikian juga efek racun perut dimana polong-polong masak susu menunjukkan tanda diserang oleh $N$. viridula. Pada pengujian terdahulu di laboratorium, aplikasi larutan minyak biji J. curcas 
Tabel 1. Rataan mortalitas N. viridula

\begin{tabular}{|c|c|c|c|c|c|c|}
\hline \multirow{2}{*}{$\begin{array}{c}\text { Perlakuan } \\
\text { Konsentrasi }\end{array}$} & \multicolumn{6}{|c|}{ Mortalitas (\%) (HSA) } \\
\hline & $1 \mathrm{HSA}$ & $2 \mathrm{HSA}$ & 3 HSA & 4 HSA & 5 HSA & 6 HSA \\
\hline $\mathrm{K}_{0}$ (Kontrol) & $0 \mathrm{~d}$ & $0 \mathrm{~d}$ & $0 \mathrm{~d}$ & $\mathrm{~d}$ & $\mathrm{~d}$ & $0 \quad d$ \\
\hline $\mathrm{K}_{1}(0,125 \%)$ & $16,66 \mathrm{c}$ & $30,00 \mathrm{c}$ & $51,66 \mathrm{bc}$ & $70,00 \mathrm{bc}$ & $86,66 \mathrm{c}$ & $86,66 \mathrm{c}$ \\
\hline $\mathrm{K}_{2}(0,25 \%)$ & $21,66 \mathrm{~b}$ & $41,66 \mathrm{~b}$ & $60,00 \mathrm{~b}$ & $80,00 \mathrm{~b}$ & $95,00 \mathrm{ab}$ & $95,00 \mathrm{ab}$ \\
\hline $\mathrm{K}_{3}(0,5 \%)$ & $28,33 \mathrm{a}$ & $56,66 \mathrm{a}$ & $75,00 \mathrm{a}$ & $91,66 \mathrm{a}$ & $98,33 \mathrm{a}$ & $100,00 \mathrm{a}$ \\
\hline
\end{tabular}

Keterangan : Angka yang diikuti oleh huruf yang sama pada kolom yang sama menunjukkan tidak beda nyata pada taraf $5 \%$ menurut Uji Beda Rata-Rata Duncan.

terhadap $N$. viridula pada 6 HSA menunjukkan mortalitas $65 \%$ pada pengujian racun kontak dan $47,5 \%$ pada pengujian racun perut dengan konsentrasi larutan 0,5\% (Asmanizar et al., 2019). Pada penelitiian ini, mortalitas $N$. viridula mencapai $100,00 \%$ pada 6 HSA. Terjadi peningkatan mortalitas $N$. viridula pada pengujian ini karena $N$. viridula diaplikasikan dengan larutan minyak biji jarak pada tanaman kedelai sehingga insektisida botanis memberikan efek pada serangga sebagai racun kontak dan racun perut. Hal ini seiring dengan laporan Bouroga (2018) bahwa minyak biji $J$. curcas juga menunjukkan efek mortalitas pada kutu tanaman setelah diberi makanan gandum yang diaplikasikan minyak jarak pada konsentrasi $2 \%$. Efek racun perut dari biji J. curcas juga dilaporkan oleh Ingle et al. (2017), bahwa mortalitas Plutella xylostella sebanyak $80 \%$ terjadi setelah diberi makan daun kubis yang dicelupkan ke dalam larutan minyak biji J. curcas pada konsentrasi $0,5 \%$. Ratnadass et al. (2009) menyatakan bahwa efek insektisidal minyak biji J. curcas terhadap Penggerek Buah Kapas Helicoverpa armigera dianggap berasal dari fraksi forbol ester yang dikandungnya. Pola mortalitas penelitian ini pada konsentrasi semprotan 0,25 dan $0,125 \%$ menunjukkan mortalitas maksimum pada 5 HSA, sedangkan konsentrasi $0,5 \%$ menunjukkan mortalitas $100 \%$ pada 6 HSA (Gambar 1 )

Hasil analisa statistik terhadap pengamatan persentase polong terserang, polong hampa, biji terserang dan produksi bji menunjukkan bahwa aplikasi minyak biji $J$. curcas dengan beberapa konsentrasi mempengaruhi semua variable yang diamati. Data ratarata persentase polong terserang, polong hampa, biji rusak dan produksi biji dapat dilihat pada Tabel 2.

Larutan minyak biji $J$. curcas dapat menurunkan persentase polong terserang hingga 90,68\% dari kontrol jika diaplikasikan pada konsentrasi 0,5\%, demikian juga pada biji terserang oleh $N$. viridula terjadi pengurangan $96,67 \%$ dari kontrol. Sedangkan polong hampa dapat menurun $55,45 \%$. Walaupun aplikasi larutan minyak biji $J$. curcas pada konsentrasi 0,125 dan $0,25 \%$ menyebabkan kematian $N$. viridula pada 6 HSA adalah 86,66 dan $95 \%$, namun sebelum mati serangga masih dapat merusak polong dan biji kedelai. Semakin kecil konsentrasi penyemprotan, maka terlihat juga peningkatan 


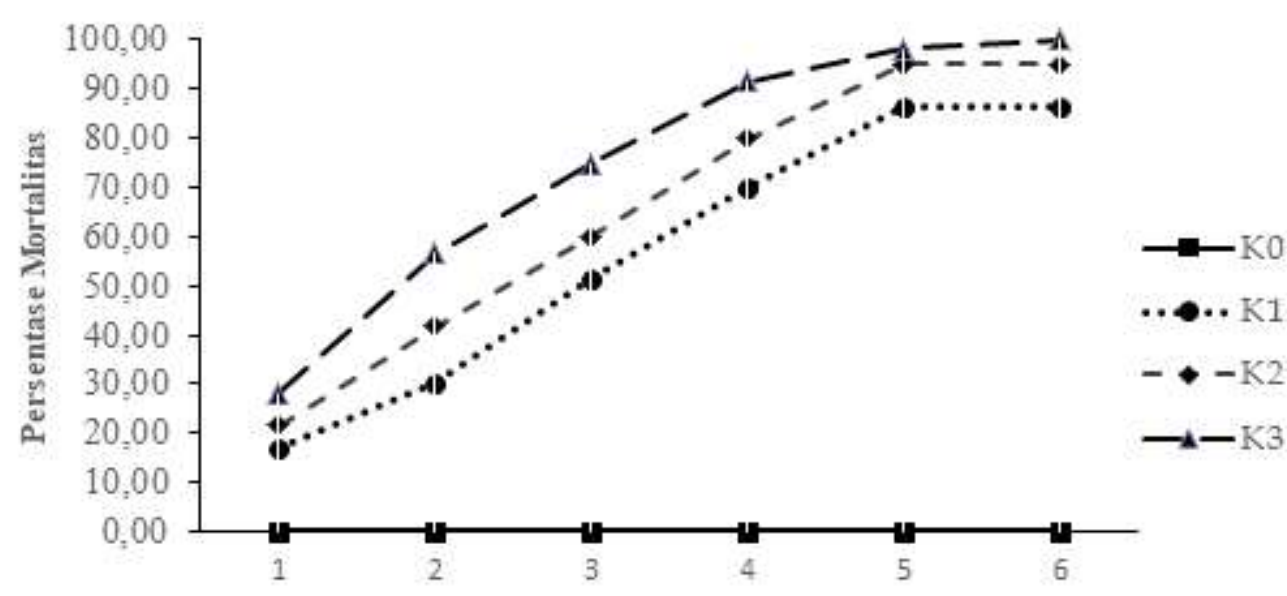

Hari Setelah Aplikasi

Gambar 1.Grafik mortalitas imago N. viridula

Tabel 2. Pengaruh aplikasi minyak biji J. curcas terhadap variable yang diamati (mortalitas $N$. viridula, persentase polong terserang, polong hampa, biji terserang dan produksi biji)

\begin{tabular}{|c|c|c|c|c|c|}
\hline Perlakuan Konsentrasi & Polong Terserang $(\%)$ & Polong & Hampa (\%) & Biji Terserang (\%) & Produksi Biji (g) \\
\hline $\mathrm{K}_{0}$ (Kontrol) & $19,74 \mathrm{a}$ & 56,84 & $\mathrm{a}$ & $23,46 \mathrm{a}$ & $5,52 \mathrm{~d}$ \\
\hline $\mathrm{K}_{1}(0,125 \%)$ & $14,0 \quad b$ & 42,20 & $\mathrm{~b}$ & $10,92 \mathrm{~b}$ & $7,36 \mathrm{c}$ \\
\hline $\mathrm{K}_{2}(0,25 \%)$ & $7,34 \mathrm{c}$ & 25,32 & $\mathrm{c}$ & $3,72 \mathrm{c}$ & $8,94 \mathrm{~b}$ \\
\hline $\mathrm{K}_{3}(0,5 \%)$ & $1,84 \mathrm{~d}$ & 25,32 & $\mathrm{c}$ & $0,78 \mathrm{~d}$ & $10,44 \mathrm{a}$ \\
\hline
\end{tabular}

Keterangan: Angka yang diikuti oleh huruf yang sama pada kolom yang sama menunjukkan tidak berbeda nyata pada taraf $5 \%$ menurut Uji Beda Rata-Rata Duncan.

kerusakan oleh $N$. viridula. Pada pengujian terdahulu di laboratorium (Asmanizar et al., 2019), minyak biji J. curcas mempunyai efek racun kontak dan racun perut pada konsentrasi 0,25 dan $0,5 \%$ terhadap $N$. viridula. Hal ini terbukti pula pada uji di rumah kasa, dimana serangga yang mati pada awal lebih dikarenakan oleh efek kontak. Pada perlakuan kontrol, serangan pada biji mencapai $23,46 \%$, namun pada aplikasi ekstrak $0,5 \%$, biji yang terserang hanya $0.78 \%$. Sifat antifeedant dari ekstrak ini dapat membuat imago $N$. viridula tidak menyerang biji. Demikian juga halnya dengan polong hampa yang disebabkan serangan $N$. viridula. Polong hampa pada perlakuan kontrol mencapai 56,84\% sedangkan pada perlakuan dengan konsentrasi 0,25 dan $0,5 \%$ adalah 25,32\%. Polong hampa pada penelitian ini adalah yang disebabkan terserang oleh $N$. viridula. Imago $N$. viridula tidak menyerang polong yang sedang pada tahap pengisian biji dimungkinkan sifat antifeedant dari minyak biji $J$. curcas. Bashir dan El Shafie(2013) melaporkan bahwa minyak biji jarak dicampurkan pada gandum dengan konsentrasi 5\% menunjukkan antifeedant indeks sebesar 78,93\%. Hal yang sama juga dilaporkan oleh Dodia et al. (2008) bahwa biji J. curcas mempunyai 
efek antifeedant terhadap hama Hyblaea puera di laboratorium. Produksi biji dapat menjadi dua kali lebih besar berbanding kontrol pada aplikasi ekstrak kasar $0,5 \%$. Pengaruh mortalitas $N$. viridula dan persentase polong hampa berkontribusi terhadap berat biji kedelai (secara kuantitas), sedangkan mortalitas $N$. viridula dan polong terserang berkontribusi terhadap biji terserang yang berimplikasi kepada kualitas biji.

\section{KESIMPULAN}

Aplikasi minyak biji J. curcas pada konsentrasi $0,5 \%$ mempunyai potensi untuk mengendalikan serangan $N$. viridula. Untuk mengetahui efektivitas tingkat lapang, maka perlu pengujian di areal pertanaman terutama pada areal pertanaman kedelai yang umum dilaksanakan petani.

\section{UCAPAN TERIMAKASIH}

Ucapan terimakasih disampaikan kepada Direktorat Riset dan Pengabdian Masyarakat, Direktorat Jenderal Penguatan Riset dan Pengembangan Kementrian Riset, Teknologi, dan Pendidikan Tinggi Republik Indonesia yang telah mendanai penelitian ini.

\section{DAFTAR PUSTAKA}

Adebowale KO and CO Adedire. 2006. Chemical composition and insecticidal properties of the underutilized Jatropha curcas seed oil. African Journal of Biotechnology 5(10):901906.
AdolfW, JJ Opferkuch and E Hecker. 1984. Irritant phorbol derivates from four Jatropha species. Phytochemistry 23:129-132.

Anonimus. 2016. Sumut Targetkan Produksi Kedelai 11,729 ton. (http://www.sumutprov.go.id). Diakses tanggal 30 April 2017.

Asmanizar, Aldywaridha, E Sumantri and RM Lubis. 2019. Potency of Jatropha curcas seed crude extract in controlling Green Stink Bug Nezara viridula (Hemiptera: Pentatomidae) a pest of soybean. Paper dipresentasikan pada The $8^{\text {th }}$ International Conference on Multidisciplinary Research International, 21st and 22nd of August 2019, Universiti Sains Malaysia, Pulau Pinang, Malaysia.

Basana IR and Prijono D. 1994. Insecticidal activity of aqueous seed extracts of four species of Annona (Annonaceae) against cabbage head caterpillar, Crocidolomia binotalis Zeller (Lepidoptera: Pyralidae). Bul. HPT 7:50-60.

Bourga F. 2018. Insecticidal properties of the physic nut tree Jatropha curcas L. (Euphorbiaceae) and potential use in pest management. Dissertation. Program for Agricultural Sciences in Goettingen (IPAG) at the Faculty of Agricultural Sciences, Georg-August-University Göttingen, Germany.

Devappa RK, MAAngulo-Escalante, HPS Makkar and K Becker. 2012. Potential of using phorbol esters as an insecticide against Spodoptera frugiperda. Ind. Crops Prod. 38, 50-53.

Dodia, DA, IS Patel and GM Patel. 2008. Botanical Pesticides for Pest Management. Jodhpur: Pawan Kumar Scientific Pub. 
Haloho H. 2014. Peluang pengembangan kedelai di Sumatera Utara. Prosiding Seminar Hasil Penelitian Tanaman Aneka Kacang dan Umbi. Balai Pengkajian Teknologi Pertanian Sumatera Utara. pp.548-556.

Ingle KP, AG Deshmukh, DA Padole, MS Dudhare, MP Moharil and VC Khelurkar. 2017. Screening of insecticidal activity of Jatropha curcas (L.) against diamond back moth and Helicoverpa armigera. Journal of Entomology and Zoology Studies. 5(1):44-50.

Isman MB. 2006. Botanical insecticide, deterrent and repellent in modern agriculture and increasingly regulated wold. Annual Review of Entomology 51:45-66.

Khalil HPSA, NAS Apprilia, AH Bhat, M Jawaid, MT Paridah and D Rudi. 2013. A Jatropha biomass as renewable materials for biocomposites and its applications. Renewable and Sustainable Energy Reviews. 22:667685.

Marwoto. 2007. Dukungan Pengendalian Hama Terpadu dalam Program Bangkit Kedelai. Balai penelitian Tanaman Kacang-kacangan dan Umbi-umbian.

Panizzi AR, JE McPherson, DG James, M Javahery and RM McPherson. 2000. Stink Bugs (Pentatomidae). In: CW Shaefer and AR Panizzi (eds.) Heteroptera of Economic Importance. CRC Press. Boca Raton. FL,USA. pp. 421-474.

Prakash A and J Rao. 1997. Botanical Pesticides in Agriculture. New York: Lewis Publishers
Prijono D. 1999. Prospek dan strategi pemanfataan insektisida alami dalam PHT. Dalam: BW Nugroho, Dadang, dan D Prijono (eds.) Bahan Pelatihan Pengembangan dan Pemanfataan Insektisida Alami. Bogor: Pusat Kajian Pengendalian Hama Terpadu, IPB. hal 1- 7.

Purwanta FX dan A Rauf. 2000. Pengaruh samping aplikasi insektisida terhadap predator dan parasitoid pada pertanaman kedelai di Cianjur. Bulletin Hama dan Penyakit Tumbuhan. 12(2):35-43.

Ramadhan RAM, LT Puspasari, R Meliansyah, R maharani, Y Hidayat dan D Donor. 2016. Bioaktivitas formulasi minyak biji Azadirachta indica (A.Juss) terhadap Spodoptera litura F. 27(1):1-8.

Ratnadass A, M Togola , B Cissé and JM Vassal. 2009. Potential of sorghum and physic nut (Jatropha curcas)for management of plant bugs (Hemiptera: Miridae) and cotton bollworm (Helicoverpa armigera) on cotton in anassisted trap-cropping strategy. Journal of SAT Agricultural Research 7.

Sudaryanto T dan DKS Swastika. 2007. Ekonomi Kedelai di Indonesia. Pusat Analisis SosialEkonomi dan Kebijakan Pertanian, Bogor.

Tengkano W dan M Soehardjan. 1985. Jenis hama utama pada berbagai fase pertumbuhan tanaman kedelai. Dalam: S Somaatmadja, M Ismunadji, Sumarno, S Mahyudin, SO Manurung, Yuswadi. (eds.) Kedelai. Puslitbangtan, Bogor pp. 295-318. 